ORIGINAL ARTICLE

\title{
Decreased cortisol response to insulin induced hypoglycaemia in asthmatics treated with inhaled fluticasone propionate
}

\author{
P Mahachoklertwattana, K Sudkronrayudh, C Direkwattanachai, L Choubtum, C Okascharoen
}

Arch Dis Child 2004;89:1055-1058. doi: 10.1136/adc.2002.020560

See end of article for authors' affiliations

Correspondence to: DrPMahachoklertwattana, Department of Pediatrics, Ramathibodi Hospital, Rama 6 Road, Bangkok, Thailand 10400; rapmw@ mahidol.ac.th

Accepted 15 February 2004
Aims: To assess adrenal function in asthmatic children treated with inhaled fluticasone propionate for up to 16 weeks.

Methods: Children with asthma and bronchial hyperresponsiveness to inhaled methacholine were treated with inhaled fluticasone $250-750 \mu \mathrm{g} /$ day via Volumatic spacer. The insulin tolerance test (ITT) was performed to assess adrenal function.

Results: Eighteen asthmatic patients (10 boys, 8 girls), aged 7-17 years received inhaled fluticasone therapy at a median dose of $477 \mu \mathrm{g} / \mathrm{m}^{2}$ per day for 5-16 weeks. Adrenal suppression, defined as 60 minute serum cortisol less than $500 \mathrm{nmol} / \mathrm{l}$, was found in 9 of 18 children. Following the ITT, the median basal and 60 minute serum cortisol concentrations of the suppressed group were 135.0 and $350.0 \mathrm{nmol} / \mathrm{l}$, respectively; the corresponding values for the unsuppressed group were 242.2 and $564.7 \mathrm{nmol} / \mathrm{l}$. Repeat ITT in the suppressed group 2-3 months after discontinuation of fluticasone revealed that all patients had a 60 minute serum cortisol greater than $500 \mathrm{nmol} / \mathrm{l}$.

Conclusion: After therapy for asthma with inhaled fluticasone at approximately $500 \mu \mathrm{g}$ daily for up to 16 weeks, half the children had evidence of adrenal suppression.
A sthma is a chronic inflammatory disease of the medium and small airways which is increasingly prevalent among children worldwide. Oral corticosteroids, which have potent anti-inflammatory actions, remain the treatment of choice for severe chronic cases. However, the adverse effects of long term administration of oral corticosteroids, in particular suppression of hypothalamic-pituitaryadrenal (HPA) axis, preclude their routine and/or prolonged use. With the advent of inhaled corticosteroids, direct and immediate delivery of the small doses to the airways is possible, resulting in fewer undesirable systemic effects. ${ }^{1}$

Inhaled fluticasone propionate is a new topically active corticosteroid, ${ }^{2}$ twice as potent as beclomethasone and budesonide. ${ }^{3}$ Systemic absorption of fluticasone through the gastrointestinal tract and the lung is low. It has been claimed that inhalation of fluticasone produces negligible side effects, including HPA axis suppression. ${ }^{5}$ Based on morning serum cortisol levels, several authors have reported no inhibition of adrenal function associated with inhaled fluticasone use, ${ }^{6-8}$ even at high doses. ${ }^{9}$ By contrast, inhaled fluticasone therapy was found to decrease urinary excretion of cortisol in one study, ${ }^{10}$ and to reduce morning serum cortisol concentration by $17-43 \%$ in another study, even at conventional doses. ${ }^{11}$ Moreover, a recent survey in the United Kingdom found that acute adrenal crisis associated with inhaled fluticasone treatment was relatively frequent, despite it being the least prescribed inhaled corticosteroid..$^{12}$

The contradictory reports as to the suppressive effect of adrenal function by inhaled fluticasone may reflect lack of sensitivity in some of the methods used. Urinary cortisol excretion and morning serum cortisol level provide information on basal endogenous adrenocortical activity only, and are not sensitive indices in predicting the ability of the HPA axis to respond to stress.

Adrenal function and its ability to respond to stress are best assessed by stimulation tests. ${ }^{13}$ The adrenocorticotropin (ACTH) test has been commonly employed to assess dynamic adrenal reserve. ${ }^{14} 15$ The standard ACTH test, using $250 \mu \mathrm{g}$ ACTH, may give false negative results in the diagnosis of partial adrenal insufficiency. ${ }^{16}$ With the low dose ACTH test, partial adrenal suppression was found in $67 \%$ of the children treated with inhaled fluticasone in doses of $750 \mu \mathrm{g}$ daily. ${ }^{17}$ This latter finding is important and requires confirmation by other methods of adrenal stimulation, such as the insulin tolerance test (ITT).

The ITT is considered by some investigators to be the gold standard in assessing the integrity of the entire HPA axis. ${ }^{16} 1819$ Since the adrenal insufficiency induced by inhaled fluticasone use is usually partial rather than complete, ${ }^{15}{ }^{16} \mathrm{a}$ sensitive test is desirable. The ITT is recognised as potentially hazardous, with reports of fatalities due to failure to take precautions against hypoglycaemia, and inappropriate glucose administration..$^{20}$ However, with full awareness of the potential risks, and the appropriate precautions and rescue measures for symptomatic hypoglycaemia, the ITT is relatively safe. ${ }^{21}$ We therefore carried out the present study to assess adrenal function using the ITT in asthmatic children treated with inhaled fluticasone after four months.

\section{METHODS}

Children with moderately severe asthma in accordance with the criteria of the American Thoracic Society, ${ }^{22}$ were enrolled in the study. They had bronchial hyperresponsiveness to inhaled methacholine ${ }^{23}$ and had been followed regularly in the Pediatric Allergy Clinic at the Faculty of Medicine, Ramathibodi Hospital, Mahidol University. Written informed consent for enrolment in the study was obtained from their parents or legal guardians. The study was approved by the Ethics Committee of the Department of Pediatrics, Faculty of Medicine, Ramathibodi Hospital.

Abbreviations: ACTH, adrenocorticotropin; HPA, hypothalamicpituitary-adrenal; ITT, insulin tolerance test 
All the patients were treated with inhaled fluticasone and bronchodilators. The dose of inhaled fluticasone was given according to the degree of response to a provocative concentration of methacholine as reported by Sont and colleagues. ${ }^{24}$ Inhaled fluticasone was given via a standard Volumatic spacer twice daily. Patients were trained to inhale the medication properly and rinse their mouths immediately after each inhalation. Medication compliance was checked with diary card records.

Only patients receiving inhaled fluticasone for up to 16 weeks were included in the study. Patients treated with other medications for asthma, including ketotifen, sodium cromoglycate, systemic corticosteroids, and other topical corticosteroids, were excluded. Patients with contraindications to the ITT, namely pre-existing primary adrenal insufficiency, disorders of the central nervous system, and seizure disorders, were also excluded.

ITT was carried out in the paediatric clinical research unit by the paediatric endocrinologist (PM). After an overnight fast, the patients were infused with intravenous regular insulin $0.1 \mathrm{U} / \mathrm{kg}$ at $8 \mathrm{am}$. Blood samples were obtained for determinations of serum cortisol at 0 minutes (basal) and 60 minutes, and for plasma glucose at $0,15,20,30,45$, and 60 minutes.

The following protocol for precautions and rescue measures for hypoglycaemia during the ITT was strictly adhered to. A physician and a nurse assistant were present throughout the testing. Clinical indications of hypoglycaemia, namely mental confusion, drowsiness, sweating, palpitations, and pupillary dilatation were closely observed. An intravenous cannula was inserted and its patency maintained throughout the testing. A bottle of $10 \%$ glucose solution was connected to the infusion line via a three-way connection ready for instant infusion. If serious adverse events (alteration of consciousness and convulsions) developed, the child was immediately given a bolus of glucose $0.5 \mathrm{~g} / \mathrm{kg}$ followed by continuous infusion of $10 \%$ dextrose solution at $0.1 \mathrm{ml} / \mathrm{kg}$ per minute until plasma glucose was maintained above $5.5 \mathrm{mmol} / \mathrm{l}$. At the end of the test, the children had to eat and remain in the research unit for one hour before cannula removal.

Serum cortisol level was determined by immunochemiluminescent assay using a commercial kit (Immulite, Diagnostic Products Corporation, Los Angeles, CA, USA). The mean intra-assay coefficient of variation was $6.1 \%$. Plasma glucose was assayed by the glucose dehydrogenase method.

The test was considered valid if the nadir plasma glucose was less than $2.2 \mathrm{mmol} / \mathrm{l}$. The criterion for adrenal suppression was a 60 minute serum cortisol value of less than $500 \mathrm{nmol} / \mathrm{l}$ during the ITT. ${ }^{15} 1625$ The laboratory reference range for basal morning serum cortisol was 140-550 nmol/l.

Statistical comparisons of parameters between the adrenal suppressed and unsuppressed groups were performed with the Kruskal-Wallis test. Multiple regression analyses were used to study relations between 60 minute serum cortisol level and other variables. A p value $<0.05$ was taken as statistically significant.

\section{RESULTS}

Eighteen children ( 10 boys and 8 girls), aged $7-17$ years, were enrolled in the study (see table 1). The duration of inhaled fluticasone treatment ranged from 5 to 16 weeks. Fourteen patients received $500 \mu \mathrm{g} /$ day of fluticasone, three received $750 \mu \mathrm{g} / \mathrm{day}$, and one $250 \mu \mathrm{g} / \mathrm{day}$. The daily dose per body surface area ranged from 221 to $735 \mu \mathrm{g} / \mathrm{m}^{2}$ with a median dose of $477 \mu \mathrm{g} / \mathrm{m}^{2}$ per day, nine patients receiving greater than and nine less than $500 \mu \mathrm{g} / \mathrm{m}^{2}$ per day. None had stigmata of Cushing's syndrome or symptoms of adrenal insufficiency.
During the ITT, most subjects had mild symptoms of hypoglycaemia (sweating and palpitations) but none developed serious adverse events (altered consciousness and convulsions). Nine children were in the suppressed group ( 60 minute cortisol $\leqslant 500 \mathrm{nmol} / \mathrm{l}$ ) and the remaining nine were in the unsuppressed group (60 minute cortisol $>500 \mathrm{nmol} / \mathrm{l}$ ). Age, daily and cumulative fluticasone doses, and duration of treatment were not statistically different between groups (see table 1). Basal serum cortisol concentrations were also significantly higher in the unsuppressed group ( $p<0.05$; see table 1 and fig 1 ), with serum morning cortisol levels within the normal range in all nine of the unsuppressed group in contrast to only four of the suppressed group. Using an increase of serum cortisol equal to or more than $200 \mathrm{nmol} / \mathrm{l}$ above the baseline value as a criterion of normal adrenal reserve, all patients in the unsuppressed group and five in the suppressed group had normal adrenal responses. Suppression of adrenal function was apparently related to the dose of inhaled fluticasone, being found in six of nine patients receiving greater than $500 \mu \mathrm{g} / \mathrm{m}^{2}$ per day and in only three of nine receiving less than this dose. Multiple regression analyses revealed that 60 minute serum cortisol values correlated negatively with dose of fluticasone $\left(\mu \mathrm{g} / \mathrm{m}^{2}\right.$ per day) $(r=-0.44, \mathrm{p}=0.027)$, and positively with basal cortisol values $(r=0.95, \mathrm{p}=0.003)$.

Adrenal function was reassessed in the suppressed group; the children underwent a second ITT 2-3 months after discontinuation of inhaled fluticasone. The duration of inhaled fluticasone therapy in this group ranged from 4 to 12 months. All had 60 minute serum cortisol greater than $500 \mathrm{nmol} / \mathrm{l}$ during the ITT (median 594; range 532-641 nmol/l), indicating recovery from adrenal suppression.

\section{DISCUSSION}

In our study, assessment of adrenal function was based on serum cortisol at 60 minutes, taking this to be the peak serum cortisol value. The reason for obtaining only one serum cortisol value at 60 minutes after insulin infusion instead of three values each at 30,60, and 90 minutes, respectively was due to a limited budget. We believe that this was acceptable, given the report of Erturk et al that serum cortisol values at 60 minutes were mostly higher than or as high as those at 30 and 90 minutes. $^{25}$

Our study shows that therapy with inhaled fluticasone in a dose of approximately $500 \mu \mathrm{g} / \mathrm{m}^{2}$ per day was associated with adrenal suppression in half the patients studied up to 16 weeks after starting treatment. This figure is slightly less than the $67 \%$ reported by Fitzgerald and colleagues. ${ }^{17}$ This

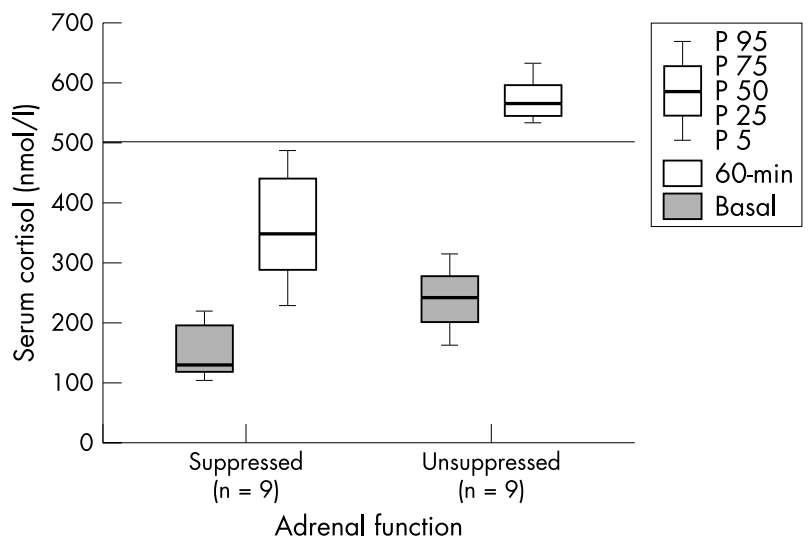

Figure 1 Median values of basal and 60 minute serum cortisol during an insulin tolerance test in asthmatic children according to adrenal suppression; 60 minute cortisol $\leqslant 500 \mathrm{nmol} / \mathrm{l}$ indicates adrenal suppression. 
Table 1 Results of insulin tolerance test in 18 asthmatic children treated with inhaled fluticasone for up to 16 weeks

\begin{tabular}{|c|c|c|c|}
\hline \multirow[b]{2}{*}{ Parameters } & \multicolumn{2}{|l|}{ Adrenal function* } & \multirow[b]{2}{*}{$\mathrm{p}$ value } \\
\hline & Unsuppressed $(n=9)$ & Suppressed $(\mathbf{n}=9)$ & \\
\hline $\begin{array}{l}\text { Age, years } \\
\text { Fluticasone inhalation }\end{array}$ & $13(7-17)$ & $10(8-16)$ & 0.53 \\
\hline $\begin{array}{l}\text { Duration, weeks } \\
\text { Dose }\end{array}$ & $14(7-16)$ & $14(5-15)$ & 0.15 \\
\hline$\mu \mathrm{g} /$ day & $500(500-750)$ & $500(250-750)$ & 0.49 \\
\hline $\begin{array}{l}\mu \mathrm{g} / \mathrm{m}^{2} \text { per day } \\
\text { Cumulative dose }\end{array}$ & $435(221-575)$ & $510(265-735)$ & 0.30 \\
\hline $\mathrm{mg}$ & $49.0(19.3-73.5)$ & $49.0(17.5-73.5)$ & 0.58 \\
\hline $\mathrm{mg} / \mathrm{m}^{2}$ & $42.5(17.0-60.4)$ & $35.5(18.4-57.6)$ & 0.51 \\
\hline Plasma glucose nadir, $\mathrm{mmol} / \mathrm{I}$ & $1.2(0.9-2.1)$ & $1.6(1.2-2.1)$ & 0.24 \\
\hline Time of glucose nadir, min & $20(15-30)$ & $20(15-30)$ & 0.55 \\
\hline Serum cortisol, nmol/I & & & \\
\hline Basal & $242.2(162.5-432.5)$ & $135.0(101.9-322.3)$ & 0.02 \\
\hline OU minute & $564.7(534.4-633.6)$ & & \\
\hline
\end{tabular}

discrepancy could be due to differences in the methods (ITT versus low dose ACTH test) and median fluticasone dose administered ( 500 versus $750 \mu \mathrm{g} /$ day). Adrenal suppression was found in only $10-16 \%$ of adult patients treated with inhaled fluticasone $220-880 \mu \mathrm{g}$ daily. ${ }^{26}$ These findings suggest that children are more vulnerable to adrenal suppression from inhaled fluticasone than adults. However, it should be remembered that children receiving the same daily doses of fluticasone to adults will be subjected to higher doses per unit body surface area. Symptomatic adrenal insufficiency is relatively common in children receiving moderate to high doses of inhaled fluticasone $(250-1000 \mu \mathrm{g} /$ day $) .{ }^{27-30}$ However, although half of the children in our study had biochemical evidence of adrenal suppression, none had symptoms of adrenal insufficiency or stigmata of Cushing's syndrome.

It is known that a higher dose and a longer duration of corticosteroid treatment increase the incidence of adrenal suppression. ${ }^{31}{ }^{32}$ The median doses received by the suppressed and unsuppressed groups in our study were not different; but more patients in the former group were on greater than $500 \mu \mathrm{g} / \mathrm{m}^{2}$ per day of fluticasone than the latter group.

At present, inhaled fluticasone is frequently prescribed for asthmatic children. To our knowledge, the present study is the first to examine adrenal status in fluticasone treated patients using the ITT. While the latter is potentially dangerous, we believe that with full awareness of the necessary precautions and rescue measures the risk is minimal, and that this method is justified in documenting the safety of inhaled fluticasone. In keeping with Galloway et al, who reported no serious adverse events with 550 ITTs over a 10 year period, ${ }^{21}$ we encountered no adverse event in the current study.

In conclusion, the present study indicates that therapy with inhaled fluticasone propionate (about $500 \mu \mathrm{g} /$ day) results in suppression of adrenal function in half of the 18 treated asthmatic children. This implies that children on fluticasone doses above the recommended amount $(400 \mu \mathrm{g} /$ day) may be at increased risk for developing acute adrenal crisis during stress. Paediatricians should be vigilant for symptoms and signs of adrenal insufficiency in such children so that prompt assessment of adrenal function and, when necessary, adrenal replacement, can be instituted.

\section{ACKNOWLEDGEMENTS}

The authors would like to thank all the patients and their parents for cooperation in the study, and Professor Phienvit Tantibhedhyangkul for the suggestion and assistance in manuscript revision. This study was funded by a grant from the Endocrine Division, Department of Pediatrics at the Faculty of Medicine, Ramathibodi Hospital.

\section{Authors' affiliations}

P Mahachoklertwattana, K Sudkronrayudh, C Direkwattanachai,

C Okascharoen, Department of Pediatrics, Ramathibodi Hospital, Faculty of Medicine, Mahidol University, Bangkok, Thailand 10400 L Choubtum, Research Center, Ramathibodi Hospital, Faculty of Medicine, Mahidol University, Bangkok, Thailand 10400

\section{REFERENCES}

1 Barnes PJ, Pedersen S. Efficacy and safety of inhaled corticosteroids in asthma. Am Rev Respir Dis 1993;148:S1-26.

2 Okamoto L, Noonan M, De Boishlance BP, et al. Fluticasone propionate improves quality of life in patients with asthma requiring oral corticosteroids. Ann Allergy Asthma Immunol 1996;76:455-61.

3 Gustafsson P, Tsanakas J, Gold M, et al. Comparison of the efficacy and safety of inhaled fluticasone propionate $200 \mathrm{mcg} /$ day with inhaled beclomethasone dipropionate $400 \mathrm{mcg} /$ day in mild and maderate asthma. Arch Dis Child 1993;69:206-11.

4 Jarvis B, Faulds D. Inhaled fluticasone propionate. A review of its therapeutic efficacy at dosages $\leqslant 500 \mu \mathrm{g} /$ day in adults and adolescents with mild to moderate asthma. Drugs 1999;57:769-803.

5 Holliday SM, Faulds D, Sorkin EM, et al. Inhaled fluticasone propionate. A review of its pharmacodynamic and pharmacokinetic properties and therapeutic use in asthma. Drugs 1994;47:318-31.

6 Hoffmann-Streb A, L'Allemand D, Niggemann B, et al. Adrenal cortex function in children with bronchial asthma in fluticasone therapy. Monatsschr Kinderheika 1993;141:508-12.

7 Ferguson AC, Spier S, Manira A, et al. Efficacy and safety of high-dose inhaled steroids in children with asthma: a comparison of fluticasone propionate with budesonide. J Pediatr 1999;134:422-7.

8 Mackenzie CA, Weinberg EG, Tabachnik E, et al. A placebo controlled trial of fluticasone propionate in asthmatic children. Eur $J$ Paediatr 1993;152:856-60.

9 Yiallouros PK, Milner AD, Conway E, et al. Adrenal function and high dose inhaled corticosteroids for asthma. Arch Dis Child 1997;76:405-10.

10 Clark DJ, Clark RA, Lipworth BJ. Adrenal suppression with inhaled budesonide and fluticasone propionate given by large volume spacer to asthmatic children. Thorax 1996;51:941-3.

11 Eid N, Morton R, Olds B, et al. Decreased morning serum cortisol levels in children with asthma treated with inhaled fluticasone propionate. Pediatrics 2002; 109:217-21.

12 Todd GR, Acerini CL, Ross-Russell R, et al. Survey of adrenal crisis associated with inhaled corticosteroids in the United Kingdom. Arch Dis Child 2002;87:457-61

13 Lipworth BJ, Seckl JR. Measures for detecting systemic bioactivity with inhaled and intranasal corticosteroids. Thorax 1997;52:476-82.

14 Boe J, Bakke P, Rodolen T, et al. High dose inhaled steroids in asthmatics: moderate efficacy gain and suppression of the hypothalamic-pituitary-adrenal axis. Research Council of the Norwegian Thoracic Society. Eur Respir J 1994;7:2179-84.

15 Broide J, Soferman R, Kivity S, et al. Low-dose adrenocorticotropin test reveals impaired adrenal function in patients taking inhaled corticosteroids. J Clin Endocrinol Metab 1995;80:1243-6.

16 Grinspoon SK, Biller BMK. Laboratory assessment of adrenal insufficiency. J Clin Endocrinol Metab 1994;79:923-31. 
17 Fitzgerald D, Asperen PV, Mellis C, et al. Fluticasone propionate $750 \mu \mathrm{g} /$ day versus beclomethasone dipropionate $1500 \mu \mathrm{g} /$ day: comparison of efficacy and adrenal function in paediatric asthma. Thorax 1998;53:656-61.

18 Fish HR, Chernow B, O'Brian JT. Endocrine and neurophysiologic responses of the pituitary to insulin-induced hypoglycemia: a review. Metabolism 1980;35:763-80.

19 Streeten DHP, Anderson GH, Dalkos TG, et al. Normal and abnormal function of the hypothalamic-pituitary-adrenocortical system in man. Endocr Rev, 1984:5:371-94.

20 Shah A, Stanhope R, Matthew D. Hazards of pharmacological tests of growth hormone secretion in childhood. BMJ 1992;304:173-4.

21 Galloway PJ, McNeill E, Paterson WF, et al. Safety of the insulin tolerance test. Arch Dis Child 2002;87:354-6.

22 American Thoracic Society. Standard for the diagnosis and care of patients with chronic obstructive pulmonary disease (COPD) and asthma. Am Rev Respir Dis 1987;136:225-44.

23 Shapiro GG, Furakawa CT, Pierson WE, et al. Methacholine bronchial challenge in children. J Allergy Clin Immunol 1982:69:365-9.

24 Sont JK, Willems LN, Bel EH, et al. Clinical control and histopathologic outcome of asthma when using airway hyperresponsiveness as an additional guide to long-term treatment. Am J Respir Crit Care Med 1999;159:1043-51.
25 Erturk E, Jaffe CA, Barkan AL. Evaluation of the integrity of the hypothalamicpituitary-adrenal axis by insulin hypoglycemia test. J Clin Endocrinol Metab 1998;83:2350-4

26 Li JTC, Goldstein MF, Gross GN, et al. Effects of fluticasone propionate, triamcinolone acetonide, prednisone, and placebo on the hypothalamicpituitary-adrenal axis. J Allergy Clin Immunol 1999;103:622-8.

27 Zimmerman B, Gold M, Wherrett D, et al. Adrenal suppression in two patients with asthma treated with low doses of the inhaled steroid fluticasone propionate. J Allergy Clin Immunol 1998;101:425-6.

28 Patel L, Wales JK, Kibirige MS, et al. Symptomatic adrenal insufficiency during inhaled corticosteroid treatment. Arch Dis Child 2001;85:330-4.

29 Drake AJ, Howells RJ, Shield JPH, et al. Symptomatic adrenal insufficiency presenting with hypoglycemia in children with asthma receiving high dose inhaled fluticasone propionate. BMJ 2002:324:1081-3.

$30 \operatorname{Sim} \mathrm{D}$, Griffiths A, Armstrong D, et al. Adrenal suppression from high-dose inhaled fluticasone propionate in children with asthma. Eur Respir $J$ 2003;21:633-6.

31 Lipworth BJ. Airway and systemic effects of inhaled corticosteroids in asthma: dose response relationship. Pulm Pharmacol 1996:9:19-27.

32 Wilson AM, Sims EJ, Lipworth BJ. Dose response with fluticasone propionate on adrenocortical activity and recovery of basal and stimulated responses after stopping treatment. Clin Endocrinol 1999;50:329-35.

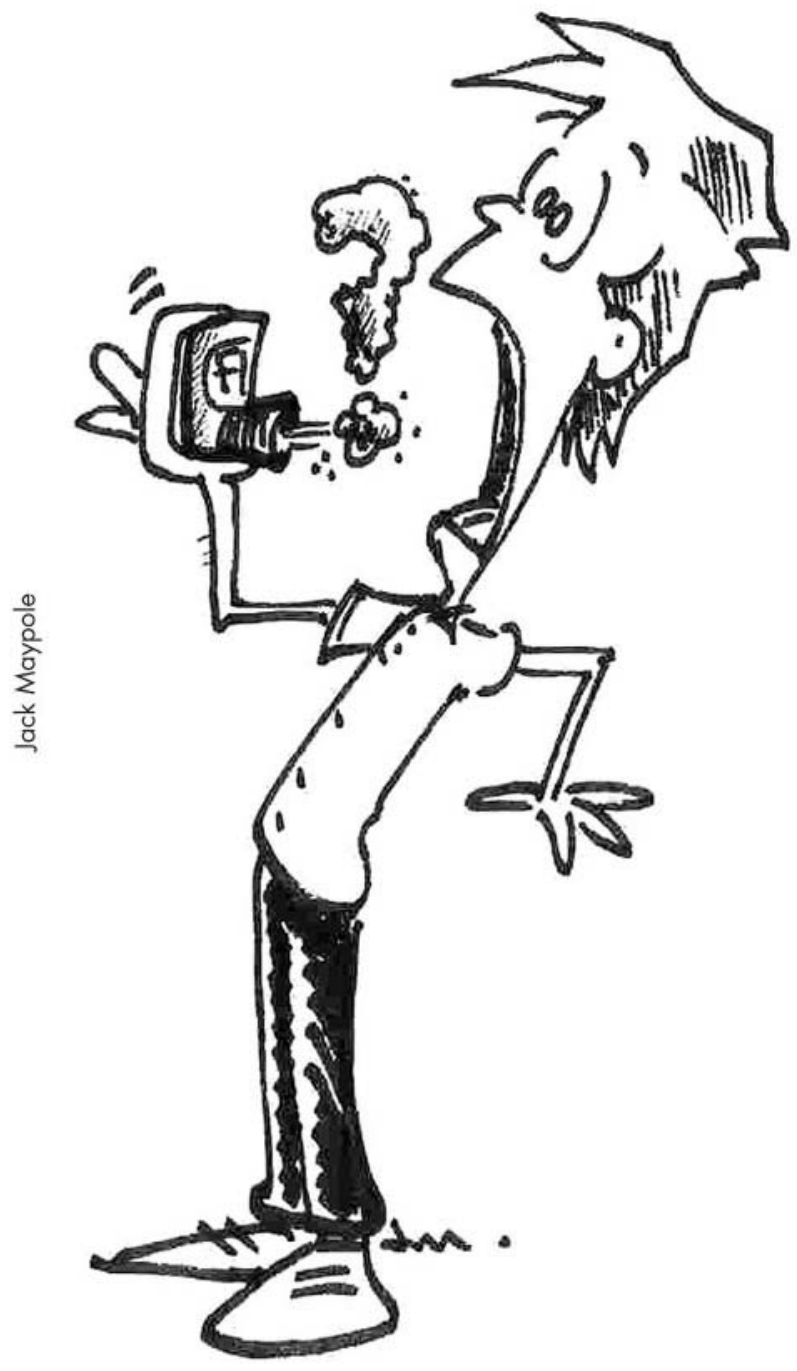

